\title{
Ten-year survival of Ugandan infants after myelomeningocele closure
}

\author{
Helen J. Sims-Williams, BMBCh, MA (Cantab), ${ }^{1}$ Hugh P. Sims-Williams, MBChB, MSc, ${ }^{1}$ \\ Edith Mbabazi Kabachelor, MBChB, MSc, ${ }^{2}$ James Fotheringham, MBChB, $\mathrm{PhD},{ }^{1}$ and \\ Benjamin C. Warf, MD³
}

\begin{abstract}
'Sheffield Teaching Hospitals NHS Foundation Trust, Sheffield, United Kingdom; ${ }^{2}$ CURE Children's Hospital of Uganda, Mbale; and ${ }^{3}$ Department of Neurosurgery, Boston Children's Hospital and Harvard Medical School, Boston, Massachusetts
\end{abstract}

\begin{abstract}
OBJECTIVE Myelomeningocele (MM) is a neural tube defect complicated by neurological deficits below the level of the spinal lesion and, in many cases, hydrocephalus. Long-term survival of infants treated for MM in a low- and middleincome country has never been reported. This retrospective cohort study reports 10 -year outcomes and factors affecting survival for infants undergoing MM repair at CURE Children's Hospital of Uganda.
\end{abstract}

METHODS Patients were traced by telephone or home visit. Survival was estimated using the Kaplan-Meier method. Multivariate survival was analyzed using the Cox proportional hazards model, investigating the following variables: sex, age at surgery, weight-for-age at surgery, motor level, and presence and management of hydrocephalus.

RESULTS A total of 145 children underwent MM repair between 2000 and 2004; complete data were available for 133 patients. The probability of 10 -year survival was $55 \%$, with $78 \%$ of deaths occurring in the first 5 years. Most of the deaths were not directly related to $\mathrm{MM}$; infection and neglect were most commonly described. Lesions at motor level L-2 or above were associated with increased mortality (HR 3.176, 95\% Cl 1.557-6.476). Compared with repair within 48 hours of birth, surgery at 15-29 days was associated with increased mortality (HR 9.091, 95\% Cl 1.169-70.698).

CONCLUSIONS Infants in low- and middle-income countries with MM can have long-term survival with basic surgical intervention. Motor level and age at surgery were significant factors influencing outcome. Education of local health care workers and families to ensure both urgent referral for initial treatment and subsequent access to basic medical care are essential to survival.

http://thejns.org/doi/abs/10.3171/2016.7.PEDS16296

KEY WORDS myelomeningocele; hydrocephalus; survival; developing world; LMIC; low- and middle-income countries; congenital

$\mathrm{M}$ YELOMENINGOCELE (MM), a primary neural tube defect, affects about one in 1000 newborns. The incidence in Uganda is unknown. However, with one of the highest birth rates in the world (total fertility 5.9 births per woman in 2013; http://data.worldbank.org/ indicator/SP.DYN.TFRT.IN) and without folate fortification or prenatal screening, the prevalence is likely to be high. ${ }^{19}$ The long-term survival for treated infants with MM has never been evaluated in any low- and middle-income countries (LMICs).
At birth, these infants have malformed spinal cord tissue exposed through a dorsal midline defect. Early closure is required to prevent infection. The spinal cord anomaly results in motor and sensory deficits below the level of the lesion (typically some degree of lower-extremity paralysis with neurogenic bladder and sphincter dysfunction). Brain development and function are variably affected by the Chiari Type II malformation, which is often associated with hydrocephalus..$^{10}$ Following surgical closure and, if needed, treatment of hydrocephalus, these children often

ABBREVIATIONS CCHU = CURE Children's Hospital of Uganda; $\mathrm{CPC}=$ choroid plexus cauterization; $\mathrm{ETV}=$ endoscopic third ventriculostomy; LMIC = low- and middleincome country; $\mathrm{MM}=$ myelomeningocele; $\mathrm{VP}=$ ventriculoperitoneal.

SUBMITTED May 31, 2016. ACCEPTED July 18, 2016.

INCLUDE WHEN CITING Published online October 21, 2016; DOI: 10.3171/2016.7.PEDS16296. 
require life-long multidisciplinary care, which is particularly challenging in the context of an LMIC.

In southeastern Uganda, an overall under-5 mortality rate of $37 \%$ was previously reported for infants with treated MM, with most deaths attributed to infectious diseases. ${ }^{19}$ Age at surgery, MM lesion level, presence of hydrocephalus (which was treated), and method of hydrocephalus treatment did not affect outcome.

This study assessed 10-year survival for a geographically defined cohort of Ugandan infants, specifically investigating the correlation with sex, age at surgical closure, weight-for-age at surgery, spinal cord lesion level, the presence of hydrocephalus, and method of hydrocephalus treatment. Our hypothesis was that a survival effect of these factors would become apparent after longer followup, having been initially obscured by the very high mortality in younger children.

\section{Methods}

\section{Study Design and Participants}

This retrospective cohort study was conducted with ethics approval from the institutional review board of CURE Children's Hospital of Uganda (CCHU).

Eligible patients were identified from the CCHU electronic database according to the following criteria: diagnosis of MM, presentation at CCHU between December 2000 and December 2004, and age younger than 6 months at the time of primary operative MM closure. To facilitate home visits, the study area was restricted to 16 districts in the southeastern region where the hospital is located (Table 1).

\section{Clinical Management}

Infants presenting to $\mathrm{CCHU}$ with MM between 2000 and 2004 usually underwent surgery within 48 hours for debridement of infected tissue and closure of the neural placode, dura, and skin. Those with a CSF leak at presentation received broad-spectrum antibiotics. Patients unwell due to meningitis or ventriculitis often required a period of stabilization before surgical repair.

From December 2000 until October 2001, all infants who developed hydrocephalus had a ventriculoperitoneal (VP) shunt placed for CSF diversion. From October 2001 until February 2003, endoscopic third ventriculostomy (ETV) was attempted as the primary treatment. ${ }^{17}$ Endoscopic fenestration through the floor of the third ventricle into the prepontine cistern creates an additional route for CSF egress from the ventricular system.

From February 2003, ETV was combined with endoscopic cauterization of the choroid plexus (CPC) in both lateral ventricles..$^{15}$ Although the exact mechanism is unclear, ETV/CPC has been shown to be more successful than ETV alone in treating hydrocephalus in these infants. ${ }^{10,15,16,18}$ A VP shunt was placed in the event of ETV (with or without CPC) failure.

\section{Data Collection}

The following information was obtained from the electronic database and review of the clinical notes: the lowest functioning spinal cord motor level at presentation, age
TABLE 1. Districts included in the study area

\begin{tabular}{lrc}
\hline & \multicolumn{2}{c}{ No. of Patients $(\%)$} \\
\cline { 2 - 3 } District & Total & Surviving to Age 10 Yrs \\
\hline Bugiri $^{*}$ & 3 & $0(0)$ \\
\hline Busia & 5 & $3(60)$ \\
\hline Iganga & 12 & $4(33)$ \\
\hline Jinja & 10 & $4(40)$ \\
\hline Kampala* & 9 & $4(44)$ \\
\hline Kamuli & 7 & $4(57)$ \\
\hline Kapchorwa & 4 & $2(50)$ \\
\hline Katakwi & 2 & $0(0)$ \\
\hline Kumi & 16 & $10(63)$ \\
\hline Mayuge & 7 & $3(43)$ \\
\hline Mbale & 24 & $8(33)$ \\
\hline Mukono & 3 & $0(0)$ \\
\hline Pallisa & 9 & $8(89)$ \\
\hline Sironko & 9 & $5(56)$ \\
\hline Soroti & 7 & $4(43)$ \\
\hline Tororo & 18 & $13(72)$ \\
\hline & 145 & 72 \\
\hline
\end{tabular}

* Outcome unknown for 2 children from Kampala and 1 from Bugiri.

and weight at surgery, the presence of hydrocephalus and method of treatment, and the date and cause of death.

Families of all patients not known to have died were telephoned or visited at home by a research assistant. For those found to have died, the date of death was ascertained from the parent(s) or, if not available, a relative or village chairperson. This individual was also asked about the cause of death and to describe the events leading up to it.

\section{Statistical Analysis}

The primary end point was patient survival from the date of MM closure. Surviving patients were censored at 10 years postsurgery. Children lost to follow-up were censored at the date last seen alive. When the exact date of death was not known, the earliest, midpoint, and latest possible dates of death were determined, and a sensitivity analysis was performed to assess changes in predictor coefficients.

Children with missing data were excluded from the survival analysis. Univariate survival was estimated using the Kaplan-Meier method. Multivariate survival was analyzed using the Cox proportional hazards model including predictor variables (for which $p \leq 0.1$ in univariate analysis) added using forward selection. The proportional hazards assumption was confirmed using log-minus-log plots. Continuous variables were all categorized. All analyses were performed using SPSS (version 22, IBM SPSS Statistics, IBM Corp.).

Variables of age at surgery were categorized based on their distributions and crude mortality rate: $0-2$ days, 3-14 days, 15-29 days, and 30 days or older. The z-score of weight-for-age at surgery was calculated for each child using WHO AnthroPlus software (http://www.who.int/ growthref/tools/en/). Following the WHO Global Data- 
base on Child Growth and Malnutrition, infants were divided into 2 categories using a $\mathrm{z}$-score cutoff of less than -2 standard deviations (corresponding to "underweight").

For motor level, children were divided into 3 groups, according to the likelihood of future ambulation. ${ }^{4}$ Children with an L-5 motor level or below would be "community ambulators," whereas those with an L-2 motor level or above would not be expected to achieve ambulation. Children with motor level L3-4 could be "household ambulators" with the assistance of orthoses and walking aids. ${ }^{4}$

\section{Results}

Between December 2000 and December 2004, 162 children from the study districts underwent primary operative MM closure at CCHU. Seventeen children older than 6 months at the time of surgery were excluded.

Review of the hospital database identified 61 children who were already known to have died. Of the remaining 84,22 were contacted by telephone and 59 by home visit. Three children could not be traced.

There were 13 instances of missing data in 12 patients, all of whom had died prior to 3 years of age. Weight at surgery was missing in 9 patients. In 4 patients, the presence of hydrocephalus could not be determined. Excluding those with missing data, 133 patients were included in the survival analysis (Fig. 1).

\section{Patient Characteristics}

Table 2 summarizes the patient characteristics; $61 \%$ of patients were male. The mean and median age at surgery were 22 and 9 days, respectively (range 1-152 days). Thirty-one infants were classified as underweight (weightfor-age z-score less than -2). The anatomical lesion was at the lumbar level or below in $90.3 \%$ of patients. The motor level was at L-2 or above in 38\%, L3-4 in 31\%, and L-5 or below in $31 \%$.

\section{Methods and Outcomes of Hydrocephalus Treatment}

Overall, 70 children (53\%) developed hydrocephalus, for which 68 underwent at least 1 surgical procedure. The remaining 2 patients did not return for scheduled treatment. One of these patients died of an unknown cause at 10 months of age and the other was lost to follow-up.

A total of 15 patients underwent ETV alone as the pri-

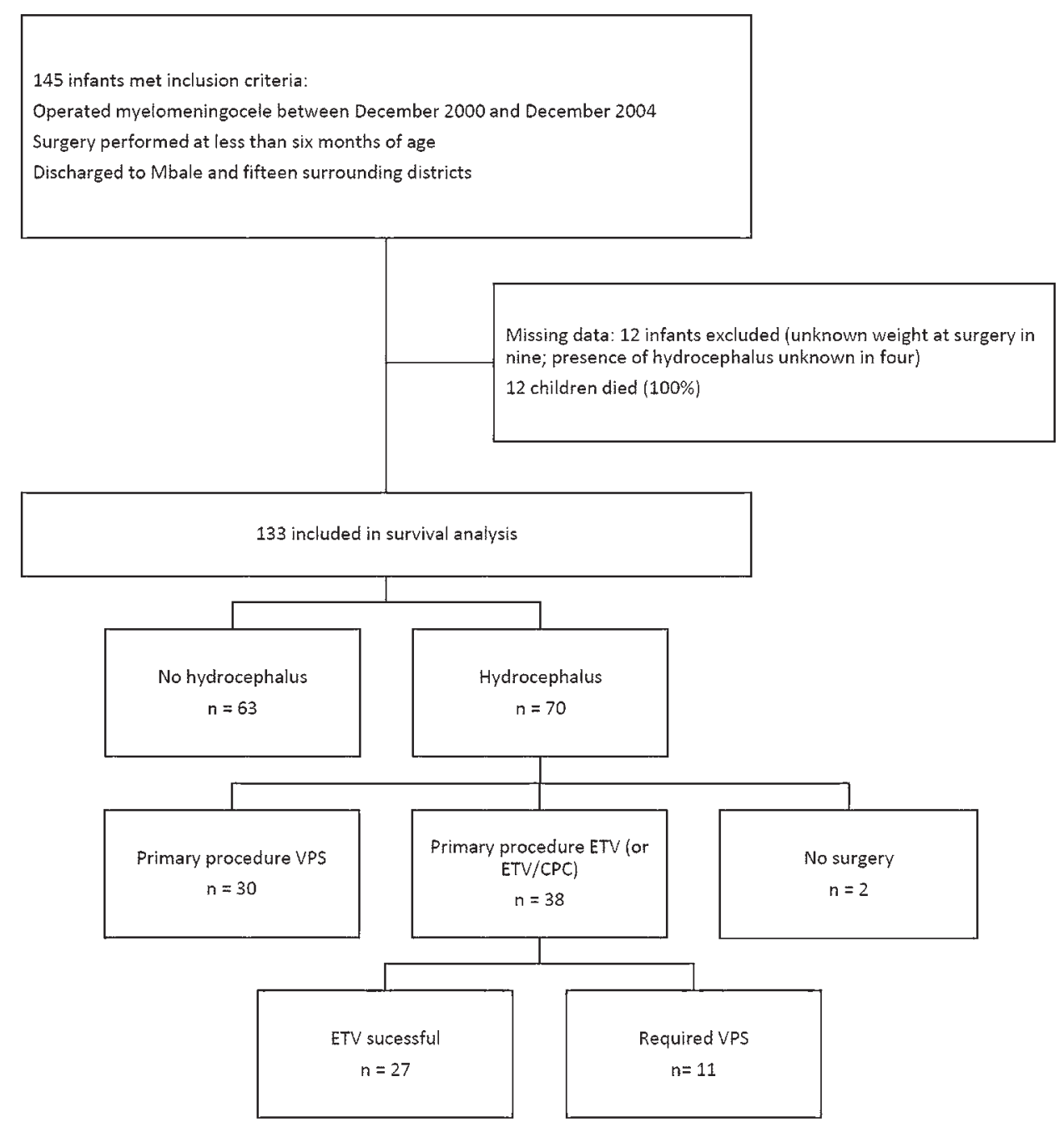

FIG. 1. Flow diagram for patient inclusion and management. VPS = VP shunt. 
TABLE 2. Patient characteristics

\begin{tabular}{|c|c|c|c|c|}
\hline \multirow[b]{2}{*}{ Variable } & \multirow{2}{*}{$\begin{array}{l}\text { Myelomeningocele } \\
\text { w/o Hydrocephalus } \\
\qquad(n=63)\end{array}$} & \multicolumn{2}{|c|}{ Myelomeningocele w/ Hydrocephalus } & \multirow{2}{*}{$\begin{array}{c}\text { All } \\
\text { Patients } \\
(n=133)^{*}\end{array}$} \\
\hline & & $\begin{array}{l}\text { Primary Treatment } \\
\text { Endoscopic }(n=38)\end{array}$ & $\begin{array}{l}\text { Primary Treatment } \\
\text { VPS }(n=30)\end{array}$ & \\
\hline \multicolumn{5}{|l|}{ Sex } \\
\hline Male & $43(68.3)$ & $19(50.0)$ & $18(60.0)$ & $81(60.9)$ \\
\hline Female & $20(31.7)$ & $19(50.0)$ & $12(40.0)$ & $52(39.1)$ \\
\hline \multicolumn{5}{|l|}{ Age at op (days) } \\
\hline $0-2$ & $6(9.5)$ & $1(2.6)$ & $0(0)$ & $7(5.3)$ \\
\hline $3-14$ & $39(61.9)$ & $25(65.8)$ & $20(66.7)$ & $85(63.9)$ \\
\hline $15-29$ & $3(4.8)$ & $8(21.1)$ & $2(6.7)$ & $14(10.5)$ \\
\hline$\geq 30$ & $15(23.8)$ & $4(10.5)$ & $8(26.7)$ & $27(20.3)$ \\
\hline \multicolumn{5}{|l|}{ Weight-for-age at op } \\
\hline z-score -2 or above & $44(69.8)$ & $33(86.8)$ & $23(76.7)$ & $102(76.7)$ \\
\hline z-score less than -2 (underweight) & $19(30.2)$ & $5(13.2)$ & $7(23.3)$ & $31(23.3)$ \\
\hline \multicolumn{5}{|l|}{ Motor level } \\
\hline L-2 \& above & $20(31.7)$ & $16(42.1)$ & $15(50.0)$ & $51(38.3)$ \\
\hline L3-4 & $19(30.2)$ & $14(36.8)$ & $7(23.3)$ & $41(30.8)$ \\
\hline L-5 \& below & 24 (38.1) & $8(21.1)$ & $8(26.7)$ & $41(30.8)$ \\
\hline
\end{tabular}

Data are number of patients (\%).

* Two patients did not have an intervention for hydrocephalus and are only included in the totals column.

mary treatment, with 7 (47\%) requiring no further surgery. Of those in whom the initial procedure had failed, one underwent a successful repeat ETV 23 days later. A VP shunt was placed in the remaining 7 patients at a median of 34 days (range 21-168 days) following ETV.

ETV/CPC was the primary treatment in 23 infants, of whom $19(83 \%)$ required no further surgery. The remaining 4 infants underwent VP shunt placement at a median of 61 days (range 14-167 days) after ETV/CPC.

Of 30 infants who had a VP shunt insertion as the primary procedure, 23 had no further surgery $(77 \%)$. Including those with failed endoscopic surgery, a total of 41 infants underwent VP shunt insertion. Among these patients, 13 patients experienced 22 complications requiring additional surgery ( 9 shunt failures and 13 shunt infections).

\section{Survival of Children After Surgically Treated MM}

Of 58 deaths in the 10 years following surgery, 25 (43\%) occurred in the 1st year and $45(78 \%)$ within 5 years (Fig. 2). Excluding the 3 children lost to follow-up, the probability of survival to 10 years postsurgery was 55\% (72/130).

The exact date of death was unknown in 14 cases: 11 deaths were known to have occurred during a certain year and 3 occurred between 2 time points more than a year apart. A sensitivity analysis performed using earliest, midpoint, and latest possible dates of death demonstrated no change in predictor coefficients, and midpoint dates were used for all further analyses.

\section{Cause of Death}

There was sufficient information to determine the cause of death in $45(78 \%)$ of 58 children (Table 3). Thirteen of these 45 deaths (29\%) could be attributed to complications of MM. Within 3 months of MM closure, 2 infants died of ventriculitis, 2 of symptomatic Chiari malformation, and 2 of aspiration pneumonia. One child died of probable bowel perforation due to constipation lasting 1 week. One 13-month-old child died of pyelonephritis. In 1 infant who had failed to return for follow-up, there was a history consistent with the development of hydrocephalus. Four children died of pressure sores, the youngest at 7 years of age. Seven deaths were attributed to neglect, which was the single most common known cause of death next to malaria. For one of these infants (a 4-year-old child), the occupational therapist from the local rehabilitation center reported, "The parents had a lot of misunderstanding in their family where the mother was battered so much by

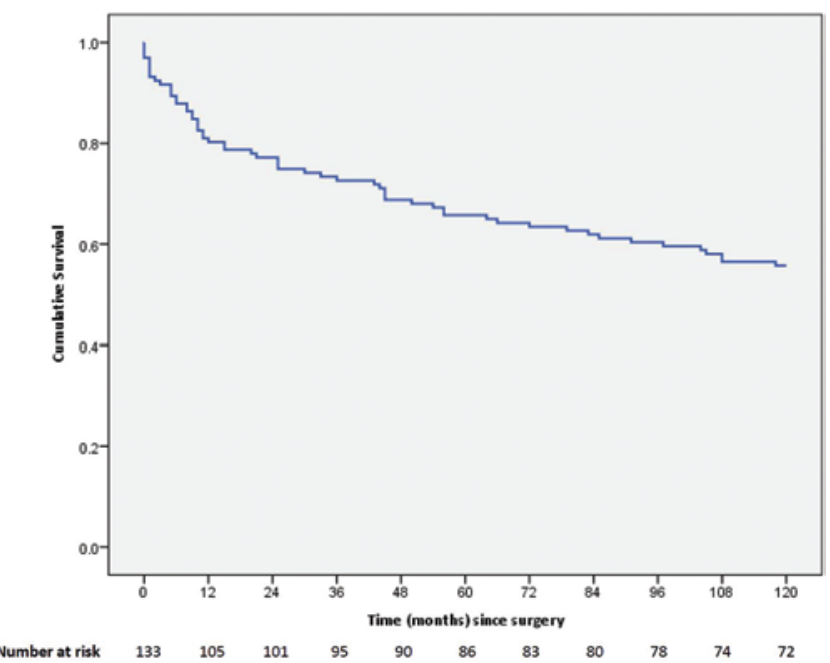

FIG. 2. Kaplan-Meier survival analysis. Figure is available in color online only. 
TABLE 3. Cause of death

\begin{tabular}{lccc}
\hline \multicolumn{1}{c}{ Variable } & $\begin{array}{c}\text { Death w/in 5 } \\
\text { Yrs (\%) }\end{array}$ & $\begin{array}{c}\text { Death Beyond } \\
5 \text { Yrs }(\%)\end{array}$ & $\begin{array}{c}\text { All Deaths } \\
(\%)\end{array}$ \\
\hline Infection & $20(44.4)$ & $5(38.5)$ & $25(43.1)$ \\
\hline Malaria & $7(15.6)$ & $2(15.4)$ & $9(15.5)$ \\
\hline Pneumonia & $4(8.9)$ & $0(0)$ & $4(6.9)$ \\
\hline Gastroenteritis & $2(4.4)$ & $0(0)$ & $2(3.4)$ \\
\hline Ventriculitis & $2(4.4)$ & $0(0)$ & $2(3.4)$ \\
\hline Other & $5(11.1)^{*}$ & $3(23.1) \dagger$ & $8(13.8)$ \\
\hline Non-infectious & $13(28.9)$ & $7(53.8)$ & $20(34.5)$ \\
\hline Hydrocephalus & $1(2.2)$ & $0(0)$ & $1(1.7)$ \\
\hline Symptomatic Chiari & $2(4.4)$ & $0(0)$ & $2(3.4)$ \\
malformation $\ddagger$ & & & \\
\hline Malnutrition/anemia & $1(2.2)$ & $1(7.7)$ & $2(3.4)$ \\
\hline Pressure sores & $0(0)$ & $4(30.7)$ & $4(6.9)$ \\
\hline Neglect§ & $5(11.1)$ & $2(15.4)$ & $7(12.1)$ \\
\hline Other & $4(8.9)$ & $0(0)$ & $4(6.9)$ \\
\hline Unknown & $12(26.7)$ & $1(7.7)$ & $13(22.4)$ \\
\hline Total & 45 & 13 & 58 \\
\hline
\end{tabular}

There were 4 postoperative deaths. Two deaths occurred as a result of aspiration pneumonia. One infant died on the day of surgery following a respiratory arrest attributed to a reaction to anesthesia. Another child died mysteriously in the night, thought to have suffocated in bed with mother.

* Other infections in the first 5 years: measles, pyelonephritis, and 3 cases of unspecified febrile illness.

† Other infections beyond 5 years: viral encephalitis and 2 cases of unspecified febrile illness.

‡ Stridor and recurrent respiratory arrest (brainstem dysfunction).

$\S$ Death due to ongoing failure by the caregiver(s) to meet the children's basic needs including nutrition and access to health care. This was determined by discussion with the family, social worker, and other local figures.

the father just because of having given birth to a child with disability.... The father did not want to see this innocent mother bringing the child for rehabilitation services.... After [the mother's] death, [the child] could not have any proper support from the father where he became malnour- ished, prone to diseases that led to his death." For another 4-year-old infant, the village chairperson reported, "Soon after the killing of the child's father (for theft), the mother neglected the child who eventually died. Mother now lives in another location."

\section{Cox Regression Model for Survival}

Motor level and age at surgery were found to be significant predictors of survival in both univariate and multivariate analyses (Table 4). There was a trend toward reduced survival with male sex, presence of hydrocephalus, and being underweight for age at surgery, but these were not statistically significant.

Children who underwent surgery within 2 days of birth had the best outcome. Mortality for those undergoing surgery at 15-29 days was significantly higher (HR 9.091, 95\% CI 1.169-70.698).

Compared with children with an initial level at L-5 and below, those with lesions at L-2 and above had significantly increased mortality (HR 3.176, 95\% CI 1.557-6.476). This was not significant for the L3-4 group (HR 1.677, 95\% CI 0.757-3.717).

\section{Comparison of Survival by Hydrocephalus Treatment Modality}

Survival of children with hydrocephalus was analyzed separately, comparing treatment modalities by intention to treat: the 11 children with VP shunt placement following ETV (with or without CPC) failure were analyzed in the ETV (with or without CPC) group.

There was no significant difference in the baseline characteristics (sex, age at surgery, weight-for-age at surgery, or motor level) between the 2 treatment groups (chisquare test).

On univariate analysis, there was no difference in survival between VP shunt and ETV (with or without CPC) treatment groups (HR 1.042, 95\% CI 0.547-1.984). Other covariates were included in a multivariate analysis; motor level was the only significant predictor of survival in this

TABLE 4. Cox regression model for survival after surgically treated myelomeningocele

\begin{tabular}{|c|c|c|c|c|}
\hline \multirow[b]{2}{*}{ Variable } & \multicolumn{2}{|c|}{ Univariate Analysis } & \multicolumn{2}{|c|}{ Multivariate Analysis } \\
\hline & $\operatorname{HR}(95 \% \mathrm{Cl})$ & $p$ Value & $\mathrm{HR}(95 \% \mathrm{Cl})$ & $\mathrm{p}$ Value \\
\hline Sex (ref: male) & $0.667(0.385-1.155)$ & 0.148 & & \\
\hline \multicolumn{5}{|l|}{ Age at op (days) } \\
\hline $0-2$ & Ref & 0.008 & Ref & 0.009 \\
\hline $3-14$ & $3.045(0.416-22.270)$ & 0.273 & $3.040(0.416-22.243)$ & 0.273 \\
\hline $15-29$ & $9.088(1.170-70.590)$ & 0.035 & $9.091(1.169-70.698)$ & 0.035 \\
\hline$\geq 30$ & $4.502(0.589-34.434)$ & 0.147 & $4.232(0.552-32.445)$ & 0.165 \\
\hline Weight-for-age at op (ref: normal weight) & $1.585(0.900-2.790)$ & 0.111 & & \\
\hline \multicolumn{5}{|l|}{ Motor level } \\
\hline L-5 \& below & Ref & 0.003 & Ref & 0.003 \\
\hline L3-4 & $1.662(0.754-3.663)$ & 0.208 & $1.677(0.757-3.717)$ & 0.203 \\
\hline L-2 \& above & $3.198(1.569-6.517)$ & 0.001 & $3.176(1.557-6.476)$ & 0.001 \\
\hline Hydrocephalus (ref: no hydrocephalus) & $1.504(0.888-2.547)$ & 0.129 & & \\
\hline
\end{tabular}

Ref = reference. 
subgroup ( $p=0.026)$. It did not significantly alter the HR for VP shunt compared with ETV (with or without CPC) (HR 1.019, 95\% CI 0.531-1.955).

\section{Discussion}

\section{Survival of Children With Surgically Treated MM}

This is the first report of long-term survival for infants with surgically treated MM from any low- or middle-income country and the largest study of its kind. Despite logistical challenges, only 3 children (2\%) were lost to follow-up. The probability of 10-year survival after MM repair was $55 \%$. Including the 12 children with missing data (all of whom died before 3 years of age), the probability of 10-year survival was 51\% (72/142). The authors are unaware of 10-year survival data for Ugandan children in the general population.

Long-term survival data for these infants in highincome countries are available from 2 other cohorts of similar size. Five-year survival in 117 unselected British infants undergoing surgery within 48 hours of birth between 1963 and 1971 was 66\%, with a steady decline in the survival curve of $3 \%$ every 5 years beyond this. ${ }^{9,12,13}$ A study of 25-year outcomes in a cohort of 118 infants in Chicago between 1975 and 1979 also found that the majority of deaths occurred in the first 5 years, with the death rate leveling off by adolescence. ${ }^{5}$ Similarly, in this Ugandan cohort, $78 \%$ of deaths occurred within the first 5 years.

Where the cause of death was known, $29 \%$ could be attributed to complications of MM, while infectious diseases accounted for more than half. We previously reported that the under-5 mortality in these children was more than double that for the general population in 2001 (141 per 1000 live births) with infectious diseases being the most common cause (http://data.worldbank.org/indicator/ SH.DYN.MORT). ${ }^{19}$

The 2011 WHO World Report on Disability showed that people with disabilities have poorer access to health care. ${ }^{21}$ This has been explained by poverty and ignorance, willful neglect, family breakdown, and stigmatization from the community. ${ }^{2,3,8,14}$ We suspect that these Ugandan children with appropriately treated MM and hydrocephalus had reduced access to basic health care and nutrition compared with their unaffected peers.

In a previous study, we estimated that patients presenting with $\mathrm{MM}$ to $\mathrm{CCHU}$ from the 3 closest districts represented only $0.24 / 1000$ live births. ${ }^{19}$ This is considerably lower than other reported incidences (for example, around 3 per 1000 in Nigeria), ${ }^{1}$ suggesting that significant numbers of infants were not brought for surgery. In other populations, MM is slightly more common in females; thus, it is interesting that $61 \%$ of our cohort was male, possibly indicating a selection bias. ${ }^{11}$

\section{Factors Predicting Survival}

Consistent with previous studies, a motor level at L-5 or below was associated with improved 10-year survival. ${ }^{12,13,20}$ Higher lesions are associated with greater disability, increasing the risk of dependence, stigmatization, and medical complications.
Earlier surgery was associated with improved survival. Prompt presentation to CCHU suggests delivery in a health care facility where the mother is immediately informed of the diagnosis and need for surgery. The more committed caregivers with sufficient financial means would be more likely to reach CCHU in time to have surgery within 48 hours. This advantage may have persisted throughout childhood.

Increased mortality among those who underwent surgery between 15 and 29 days may reflect a delay in presentation. In addition, surgery was sometimes postponed due to established central nervous system infection until patients were stable. Survival in children who underwent surgery after 30 days was not significantly worse, likely due to selection for infants avoiding or surviving an initial central nervous system infection, with subsequent epithelialization of the lesion.

\section{Management of Hydrocephalus}

The incidence of hydrocephalus in this cohort (53\%) is lower than that reported in older series but is consistent with more recent studies that likely reflect evolving treatment indications. ${ }^{6}$ We found no significant difference in 10-year survival between children whose initial treatment was ETV (with or without CPC) and VP shunt. ETV/CPC was successful in $83 \%$, with no additional operations and no evidence of late treatment failure over 10 years. Of the 41 children who ultimately had a VP shunt, there were 22 complications requiring surgery in 13 children (32\%).

The presence of a shunt has been found to negatively impact outcomes into adulthood. ${ }^{5,7}$ Longer follow-up may demonstrate a survival benefit of shunt independence, particularly in this cohort with very limited access to emergency shunt revision surgery.

\section{Limitations}

The study is limited by its retrospective nature. Thirteen instances of missing data required the exclusion of 12 children from the final analysis, resulting in an overestimation of 10-year survival at 55\% (rather than 51\% when all children were included). However, this did not significantly alter the shape or appearance of the Kaplan-Meier curve.

Since the majority of children did not die in the hospital, we relied on the account given by parents or another available adult, which would be subject to recall bias. In some cases (predominantly deaths in the first 5 years), no information was available.

\section{Conclusions}

Over half of these Ugandan infants survived at least 10 years after MM closure. Most deaths occurred in the first 5 years and were not a direct result of the anomaly. Lesions at motor level L-5 or below and MM repair within 2 days of birth were associated with significantly improved survival. Local health care workers should be trained to facilitate urgent referral. The survival impact of parental and community attitudes and behaviors must be better understood, and the inequality experienced by individuals with disabilities needs to be addressed at a societal level to improve long-term outcomes for these children. 


\section{Acknowledgments}

We acknowledge the assistance of Hellen Titin, Ezra Bamulikulwaki, Rebecca Muduwa, and Moses Mukalo in the conduct of this study.

Dr. Helen J. Sims-Williams has been awarded the Thomas Watts Eden Paediatric Fellowship by the Royal College of Physicians (London). Patient follow-up was supported through Dr. Benjamin C. Warf's John D. and Catherine T. MacArthur Fellowship award.

\section{References}

1. Airede KI: Neural tube defects in the middle belt of Nigeria. J Trop Pediatr 38:27-30, 1992

2. Alatise OI, Adeolu AA, Komolafe EO, Adejuyigbe O, Sowande OA: Pattern and factors affecting management outcome of spina bifida cystica in Ile-Ife, Nigeria. Pediatr Neurosurg 42:277-283, 2006

3. Bannink F, Stroeken K, Idro R, van Hove G: Community knowledge, beliefs, attitudes, and practices towards children with spina bifida and hydrocephalus in Uganda. Int J Disabil Dev Educ 62:182-201, 2015

4. Bartonek A, Saraste H: Factors influencing ambulation in myelomeningocele: a cross-sectional study. Dev Med Child Neurol 43:253-260, 2001

5. Bowman RM, McLone DG, Grant JA, Tomita T, Ito JA: Spina bifida outcome: a 25 -year prospective. Pediatr Neurosurg 34:114-120, 2001

6. Chakraborty A, Crimmins D, Hayward R, Thompson D: Toward reducing shunt placement rates in patients with myelomeningocele. J Neurosurg Pediatr 1:361-365, 2008

7. Davis BE, Daley CM, Shurtleff DB, Duguay S, Seidel K, Loeser JD, et al: Long-term survival of individuals with myelomeningocele. Pediatr Neurosurg 41:186-191, 2005

8. Hartley S, Ojwang P, Baguwemu A, Ddamulira M, Chavuta A: How do carers of disabled children cope? The Ugandan perspective. Child Care Health Dev 31:167-180, 2005

9. Hunt GM: The median survival time in open spina bifida. Dev Med Child Neurol 39:568, 1997 (Letter)

10. Kahle KT, Kulkarni AV, Limbrick DD Jr, Warf BC: Hydrocephalus in children. Lancet 387:788-799, 2016

11. Lary JM, Edmonds LD: Prevalence of spina bifida at birthUnited States, 1983-1990: a comparison of two surveillance systems. MMWR CDC Surveill Summ 45:15-26, 1996

12. Oakeshott P, Hunt GM, Poulton A, Reid F: Open spina bifida: birth findings predict long-term outcome. Arch Dis Child 97:474-476, 2012

13. Oakeshott P, Reid F, Poulton A, Markus H, Whitaker RH, Hunt GM: Neurological level at birth predicts survival to the mid-40s and urological deaths in open spina bifida: a complete prospective cohort study. Dev Med Child Neurol [epub ahead of print], 2015

14. Oyewole A, Adeloye A, Adeyokunnu AA: Psychosocial and cultural factors associated with the management of spina bifida cystica in Nigeria. Dev Med Child Neurol 27:498-503, 1985

15. Warf BC: Comparison of endoscopic third ventriculostomy alone and combined with choroid plexus cauterization in infants younger than 1 year of age: a prospective study in 550 African children. J Neurosurg 103 (6 Suppl):475-481, 2005

16. Warf BC: Hydrocephalus associated with neural tube defects: characteristics, management, and outcome in sub-Saharan Africa. Childs Nerv Syst 27:1589-1594, 2011

17. Warf BC: Hydrocephalus in Uganda: the predominance of infectious origin and primary management with endoscopic third ventriculostomy. J Neurosurg 102 (1 Suppl):1-15, 2005

18. Warf BC, Campbell JW: Combined endoscopic third ventriculostomy and choroid plexus cauterization as primary treatment of hydrocephalus for infants with myelomeningocele: long-term results of a prospective intent-to-treat study in 115 East African infants. J Neurosurg Pediatr 2:310-316, 2008

19. Warf BC, Wright EJ, Kulkarni AV: Factors affecting survival of infants with myelomeningocele in southeastern Uganda. J Neurosurg Pediatr 7:127-133, 2011

20. Wong LY, Paulozzi LJ: Survival of infants with spina bifida: a population study, 1979-94. Paediatr Perinat Epidemiol 15:374-378, 2001

21. World Health Organization: World Report on Disability. Geneva: World Health Organization, 2011 (http://www.who. int/disabilities/world_report/2011/en/) [Accessed August 16, 2016]

\section{Disclosures}

The authors report no conflict of interest concerning the materials or methods used in this study or the findings specified in this paper.

\section{Author Contributions}

Conception and design: Warf, Helen Sims-Williams, Hugh Sims-Williams. Acquisition of data: Helen Sims-Williams, Hugh Sims-Williams, Kabachelor. Analysis and interpretation of data: Warf, Helen Sims-Williams, Hugh Sims-Williams, Fotheringham. Drafting the article: Warf, Helen Sims-Williams. Critically revising the article: all authors. Reviewed submitted version of manuscript: all authors. Approved the final version of the manuscript on behalf of all authors: Warf. Statistical analysis: Helen Sims-Williams, Fotheringham. Administrative/technical/material support: Warf, Kabachelor. Study supervision: Warf.

\section{Correspondence}

Benjamin C. Warf, Department of Neurosurgery, Boston Children's Hospital, 300 Longwood Ave., Boston, MA 02115. email: benjamin.warf@childrens.harvard.edu. 